Kавакоva, Galina (ed.): Contes et légendes étiologiques dans l'espace européen. París: Pippa / Flies France, 20I3, 304 p.

\title{
Contes et légendes étiologiques dans l'espace européen
}

Camiño Noia CAMPOS

Universidade de Vigo, Vigo

El llibre reuneix els treballs presentats al primer col-loqui pluridisciplinari consagrat als relats etiològics que es va celebrar a la Universitat de París-Sorbona a l'octubre de 2012.

S'entenen per relats etiològics aquells que conten una breu història en la qual s'explica l'origen d'un fenomen de la natura, que la humanitat analfabeta només podia entendre mitjançant una narració, sigui el naixement del sol, les taques de la lluna, un llac, una muntanya, una roca; la mort, característiques d'alguns animals (esterilitat del burro, manca de potes de la serp, el cant d'ocells...) o d'humans (en especial de defectes de la dona); i, encara que en menor quantitat, certes realitats socials com la misèria (AaTh 330D Bonhomme Misere) o la injustícia. Tot i la unitat que els confereix l'origen didàctic (explicatiu), aquest conjunt de relats difereixen per antiguitat, contingut i gènere literari en què es transmeten. Uns procedeixen d'antics mites del paganisme i altres sorgeixen, o es reelaboren, a partir de l'expansió del Cristianisme i mostren com Déu, Nostre Senyor, la Verge Maria o els seus sants premien o castiguen els humans segons si realitzen bones o males obres. En alguns casos, els mateixos personatges i el dimoni protagonitzen contarelles humorístiques sobre defectes o circumstàncies ridícules, en general, sobre sant Pere i sobre dones. Com he pogut observar en col-leccions de rondalles d'àrees lingüístiques de la península Ibèrica, la misogínia és freqüent en els etiològics.

El discurs etiològic, com d'altres, va circular des de l'època medieval en textos escrits en paral-lel a la transmissió oral. En són una bona mostra els exemplaris i faularis de caràcter didàctic que indiquen com van ser reelaborades històries paganes de l'oralitat a través de l'escriptura; històries que, difoses als púlpits, van tornar a l'audiència popular. Tot i això, ni els eclesiàstics — potser en l'afany per difondre les històries bíbliques- ni, més tard, l'etnologia o la folklorística es van interessar per aquests contes breus, en molts casos còmics, que expliquen el perquè d'elements de la natura o els defectes i virtuts d'humans i animals. En l'extensa col-lecció de contes alemanys dels germans Jakob i Wilhelm Grimm, que va servir de model per a posteriors antòlegs de narrativa oral, hi ha un nombre molt reduït de relats etiològics. La d'Alexandre Afanassiev (I855-I863), que recull siscents contes populars russos, només n'inclou dos de caràcter etiològic.

Amb la publicació l'any i 898 d'una antologia de cent vint relats etiològics sobre l'origen de certs animals i de fenòmens de la natura, l'alemany Oskar Dähnhardt es converteix en el primer col-lector d'aquest tipus d'històries. I a partir d'aquesta antologia de cent vint relats explicatius sobre la natura, inicia l'elaboració d'una altra de molt més extensa composta per rondalles, llegendes i faules, que publica en una voluminosa obra titulada Natursagen eine Sammlung naturdeutender Sagen, Märchen, Fabeln und Legender (I907-I9I2), en la qual fa la primera temptativa de sistematització d'aquests textos. Un treball que gairebé no va tenir repercussió en 
els anys que van seguir a la seva aparició, sens dubte perquè en aquells moments Europa estava en vigília de la Primera Guerra mundial, però també per la mort, el I9I5, del seu autor. El treball de Dähnhardt va ser rescatat anys més tard per investigadores del folklore com Marie-Louise Tenèze, que, davant les carències del catàleg internacional d'Aarne i Thompson en aquest tipus de relats, agrupa els contes explicatius francesos en «relats pròpiament etiològics» $\mathrm{i}$ «relats arbitràriament etiològics» per a rondalles que afegeixen una finalitat explicativa que no tenien en origen, seguint els criteris de Dähnhardt. La difusió del catàleg de Tenèze en l'àmbit de la folklorística europea difondrà la proposta de sistematització de Dähnhardt i serà utilitzada en col-leccions posteriors de narrativa etiològica.

En l'afany per conservar la cultura immaterial catalana, durant la primera meitat del segle xx, el folklorista Joan Amades (I890-I959) recull una extensa collecció de rondalles, entre les quals n'hi ha un important nombre d'etiològiques que expliquen l'origen de les característiques de certs animals i plantes. Com els folkloristes anteriors, Amades no va donar cap més importància al discurs etiològic que el de ser una manifestació de la cultura ancestral del poble català i els relats que porten aquest discurs apareixen entre la resta de creences populars. La publicació el I988 i I995 de la traducció francesa de Marlène Albert-Llorca de dues col-leccions de relats etiològics catalans recollits per Amades (L'origine des bêtes i Des étoiles aux plantes) n'amplia la difusió a Europa.

Amb la informació obtinguda en el seu treball de traducció de les històries etiològiques catalanes sobre l'origen de característiques d'animals i plantes, unida a la que obté de tradicions d'altres països durant el procés d'elaboració de la tesi doctoral, Albert-Llorca escriu el llibre L'ordre des choses: les récits d'origine des animaux et des plantes en Europe, publicat el I99I. Una obra en la qual tracta d'interpretar com i per què els humans analfabets van expressar les seves idees sobre la natura, i explica l'enorme influència exercida pel cristianisme en la cultura europea, no com a institució, sinó com a doctrina, «la pensée sauvage du christianisme», en paraules de l'autora. La seva documentada informació ens permet acostar-nos al pensament i a les creences populars de les antigues comunitats rurals, i aconsegueix que en la darrera dècada del segle xx el discurs etiològic comenci a produir nous treballs de recollida de textos i de recerca.

De tot això i més tracta el llibre Contes et légendes étiologiques dans l'espace européen, editat per Galina Kabakova amb vint-i-tres articles en els quals els estudiosos tracten diferents aspectes al voltant dels relats etiològics; articles que l'editora distribueix en tres apartats: «Découvrir, classer, contextualiser», "Motifs et personnages du récit étiologique» $\mathrm{i}$ «Le discours étiologique à travers les siècles».

El primer recull tres treballs de les conegudes folkloristes Marlène Albert-Llorca, Elena Balzamo i Carme Oriol. Com hem vist abans, dedicada des de fa més de trenta anys a la recopilació, traducció i anàlisi de relats etiològics, Albert-Llorca es refereix, en primer lloc, a la identitat d'aquest tipus de relats a partir del concepte polivalent de «popular» amb el qual s'acostuma a definir-los («savieses populars») i al seu possible estatus en relació amb els mites per la utilització de diferents gèneres (subgèneres) narratius per explicar una història amb finalitat etiològica, llegendes religioses, rondalles humorístiques i rondalles d'animals; a continuació, se centra en les dificultats de classificació que plantegen els textos etiològics recordant els intents duts a terme en la dècada dels anys vuitanta per part d'investigadores d'antropologia i etnologia a partir de la proposta de sistematització 
de Dähnhardt. Elena Balzamo ens descobreix que en les col-leccions de rondalles dels països nòrdics (Noruega, Suècia, Dinamarca i Islàndia) fetes en el segle xıx no hi apareixen textos etiològics, una constatació que la va animar a promoure la publicació de dues col-leccions, una de relats de diversos països europeus (2005) i una altra de relats suecs (2006). Tot i les temptatives de classificació realitzades dels textos etiològics, tant per les dificultats que n'ofereix la distinta naturalesa com per l'absència en les col-leccions de rondalles, no disposem encara d'una que estigui acceptada internacionalment. Carme Oriol, experta catalogadora de narrativa oral, presenta en el seu article una nova temptativa de classificació dels relats explicatius catalans un cop analitzades les propostes de sistematització d'aquest tipus de relats fetes per Linda Dégh, Marie-Louise Tenèze, Hannjost Lixfelt, Marlene Albert-Llorca i Heda Jason. La proposta d'Oriol estableix quatre grups en els quals s'integren tots els textos explicatius: relat etiològic i tradició explicativa, situació explicativa i text informatiu. Sota la denominació de «relat» s'hi integren històries en les quals no és fàcil diferenciar si es tracta de rondalles o de llegendes; amb el terme «tradició explicativa», utilitzat majoritàriament pels folkloristes catalans, s'agrupen llegendes, tradicions locals i altres tradicions folklòriques; «situació explicativa» inclou relats d'altres gèneres que acaben amb una frase proverbial i en el «text informatiu» s'hi integrarien enunciats que contenen una breu informació sobre un costum o una creença popular.

En el segon apartat del llibre, que és el més extens dels tres, catorze articles estudien motius i personatges característics del relat etiològic. Nou d'ells fan referència a aspectes relacionats amb les diferents tradicions dels països eslaus. Els seus autors i autores, en general, fa anys que treballen sobre narrativa oral en els seus països. Elena Boganeva analitza llegendes etiològiques sobre la nativitat i la fugida a Egipte de la Sagrada Família gravades en els darrers quinze anys en totes les regions de Bielorrússia. Olesja Britsyna, que entre els anys 2003 i 2012 ha recollit narracions al nord d'Ucraïna (Polèsia), estudia les relacions entre l'oralitat i l'escriptura en relats etiològics, que encara es transmeten, sobre l'origen dels animals i dels ocells, sobre certs fenòmens de la vida social (ATU 98I) i de la naturalesa, i ha pogut constatar que els informants donen més importància a l'element moralitzador que a l'etiològic. Alexandre Gura es refereix a la llegenda sobre el matrimoni anul-lat del sol que circula entre els pobles balcànics i bàltics, majoritàriament en versions en prosa, però també en versions cantades. La cerca de l'origen d'aquest motiu cosmogònic, en especial el paper de l'ase que apareix en les llegendes, va conduir-lo a fonts literàries de l'antiguitat clàssica (la novel·la d'Apuleu) i a analitzar el simbolisme solar que es dóna als passatges dedicats a l'entrada de Crist a Jerusalem del Nou Testament.

L'anàlisi de diferents corpus etiològics va portar investigadors i investigadores a interessar-se per narracions que es refereixen a la creació i al personatge del creador. Olga Belova, que ha reunit en una «bíblia popular» (publicada a Moscou el 2004) totes les tradicions eslaves orientals, ens mostra com l'etiologia és un dels elements imprescindibles en les narracions folklòriques de les llegendes cosmogòniques eslaves, en especial les històries d'una cocreació, és a dir, una gènesi dual en la qual Déu i el seu adversari (Satan) o el seu ajudant (sant Pere) creen el món, conjuntament o en oposició. Zmago Smitek descobreix en llegendes etiològiques eslovenes sobre la creació que no sempre es presenta com el motiu del qual es parteix, sinó com una intervenció divina per corregir alguna cosa que 
afecta l'harmonia del món, de manera que, per exemple, Déu ha de posar fi a la comunicació entre els humans i la naturalesa privant-la del do de la paraula. Patrice Lajoye s'ocupa també de llegendes sobre la creació de les muntanyes balcàniques; en aquest cas, atribuïda a l'eriçó i a l'abella, comparant els motius de les narracions balcàniques amb els de narratives de les tradicions hindú, irlandesa i del País de Gal·les, la qual cosa li permet pensar que els motius d'animals presents en les etiologies europees poden estar relacionats amb l'antic fons mitològic indoeuropeu. Per la seva part, Caterina Valriu estudia les tipologies temàtiques en relats que expliquen la creació del món extrets de textos narratius recollits en els tres volums del Folklore de Catalunya (I95O) i els cinc del Costumari català (I952) de Joan Amades, i constata que, com succeeix en les tradicions eslaves (Olga Belova) i en les irlandeses (Patrice Lajoye), també en la catalana hi ha present el model dualista de creador del món i amb el mateix funcionament. Svetlana Tolstaïa se centra en els motius etiològics que apareixen en llegendes i creences sobre la mort en la tradició dels pobles eslaus d'Orient i arriba a la conclusió que el tema etiològic rellevant a tot Europa és la resposta a «per què no es pot conèixer per endavant el moment de la mort». Tatjana Volodina analitza les llegendes antropogòniques bielorusses que apareixen en les representacions populars i en les pràctiques màgiques i observa la relació que existeix entre la medicina tradicional i els relats sobre la creació dualista dels primers humans, relació que justifica la utilització d'algunes tècniques mèdiques tradicionals. A partir d'una àmplia col·lecció de textos recollits de la tradició oral a Polònia, Lituània, Bielorrússia i Ucraïna entre els anys I980 i 2000, Magdalena Zowezak exposa els resultats de la seva recerca sobre la interpretació del temps en llegendes etiològiques d'aquests països i mostra que, encara que en el discurs etiològic és prioritari justificar l'ordre de les coses, de vegades la intenció es dirigeix a construir la identitat del país. Dins del món eslau cal incloure també l'article de Galina Kabakova, que, tot i el seu títol i el coneixement que, sens dubte, té del món francès, exemplifica les seves reflexions sobre els motius de la distribució i dels destins en el relat europeu amb exemples de països eslaus. Pels seus llargs anys de recerca en aquest àmbit, Kabakova sap que un gran nombre de motius etiològics circula per àrees lingüístiques molt àmplies, més enllà de la cultura judeocristiana, i suggereix la necessitat d'elaborar una enciclopèdia de motius universals.

Completen la segona part del llibre els articles de Daniel Giraudon i Bengt af Klintberg que es refereixen a relats etiològics sobre ocells (l'alosa, l'oreneta, el cabussó i la gélinotte) en les tradicions orals bretona i francesa. Giraudon parla del mimologisme (expressió que tradueix en llenguatge humà el cant o crit d'un animal) del cant de l'alosa present en la cultura pagesa bretona. Es diu que, en volar cap amunt, l'alosa dirigeix el seu cant a sant Pere perquè li obri la porta del cel i li assegura que no tornarà a pecar, i en descendir clama a Déu per no obrir-la-hi i afirma que continuarà pecant. Bengt af Klintberg busca els orígens cristians o precristians dels motius etiològics en diferents versions de tres llegendes escandinaves a través de la figura del demiürg, i arriba a la conclusió que certes intervencions van ser atribuïdes a personatges del cristianisme quan es va implantar a Escandinàvia. Claude Lecouteux estudia les etiologies de la tradició romanesa: les d'influència cristiana, les d'origen pagà, les etiologies humorístiques i les lingüístiques. 
El tercer apartat del llibre, amb cinc articles, s'inicia amb el de Nicolas Balzamo referit a mites medievals i a la relació que tenen amb relats populars i històrics sobre fundacions, i constata que la fundació de monestirs i seus episcopals se sol atribuir a un sant de l'època apostòlica mentre que la d'universitats i ciutats és assignada a un poderós heroi. Pierre Gonneau ens revela com el discurs etiològic fou utilitzat en les cròniques russes per legitimar accions polítiques, i posa com a exemple el relat que fan de l'expansió militar d'Ivan el Terrible i la conquesta de Kazan, en la segona meitat del segle XVI; unint l'etiologia a l'escatologia utilitzen el mite del niu de la serp per justificar la massacre sobre els tàrtars, adversaris històrics de Rússia. Florent Mouchard observa que els llibres apòcrifs que evoquen els orígens del món i la seva fi van tenir una gran difusió per tota l'Europa cristiana, una dada que li permet formular la hipòtesi d'una possible influència en la predicació del monjo rus del segle XIII, Abraham de Smolensk, perseguit per les seves lectures blasfemes. Alexandre Stroev analitza els mites i les metamorfosis de l'antiguitat que refereixen alguns textos literaris francesos i russos del segle XVIII i constata la coexistència que existeix entre la tradició llibresca, en especial de les Metamorfosis d'Ovidi, amb les llegendes antigues, rondalles i apòcrifs cristians que circulen en l'oralitat.

L'article d'Anna Stroeva-Habib canvia el rumb dels treballs precedents per parlar de la inclusió del discurs etiològic en el llenguatge publicitari del comerç per part d'algunes marques del sector de l'alimentació.

El llibre es conclou amb l'experiència d'una contadora eslava de contes etiològics referida per Anastasia Ortenzio.

L'interès de Contes et légendes étiologiques dans l'espace européen resideix en l'àmplia i rigorosa informació que conté sobre una varietat de temes relacionats amb el discurs etiològic, un interès que s'acreix per a les persones que treballem en etnografia i en narrativa oral. Però, sense que això suposi un demèrit per a l'obra, cal assenyalar que el títol ens porta a pensar que es tractaran tradicions europees d'un espai més ampli del que apareix a l'interior, ja que, amb l'excepció de la catalana, la francesa i la bretona, la resta de treballs es refereixen a les diverses tradicions agrupades en el variat món de països eslaus i deixen fora àmplies àrees lingüístiques de l'Europa del nord i del sud amb importants tradicions culturals, orals i escrites.

Per concloure, vull insistir en la necessitat de disposar d'una classificació que sistematitzi l'abundància de motius, temes i personatges que existeixen en els relats etiològics, com assenyala Galina Kabakova. Una classificació que podria ser la que proposa Carme Oriol, un cop debatuda per folkloristes i catalogadors de diversos països europeus i que aconseguís un reconeixement internacional. Un sistema classificatori que podria afegir-se al catàleg internacional de tipus rondallístics d'Aarne-Thompson-Uther com un nou apartat o com un índex tipològic de relats etiològics independent. 